\title{
LIFE CYCLE ASSESSMENT FOR SUSTAINABLE DESIGN OF RAILWAY INFRASTRUCTURES. A CASE STUDY APPLICATION IN EDUCATION
}

\author{
J.J. Pons ${ }^{1}$, V. Yepes ${ }^{1}$, P. Salvador-Zuriaga ${ }^{2}$, R. Insa-Franco ${ }^{2}$ \\ ${ }^{1}$ ICITECH. Dept. Ingeniería de la Construcción y Proyectos de Ingeniería Civil. Universitat \\ Politècnica de València (SPAIN) \\ ${ }^{2}$ Dpto. de Ingeniería e Infraestructura de los Transportes. Universitat Politècnica de València
}

(SPAIN)

\begin{abstract}
The following article deals with the introduction of the life cycle assessment applied to design sustainable infrastructure. Particularly, it is applied in the Railways course of the Bachelor's Degree in Civil Engineering from the Universitat Politècnica de València, on which students are introduced to the construction, operation and maintenance of railway infrastructures. Traditionally, for the design of any infrastructure, only economic criteria have been considered, mainly the initial construction cost. However, since they last over time, the cost through the entire life cycle, from the production of materials to the demolition of the infrastructure itself, must be analyzed. Additionally, due to the climatic and social challenges caused by global warming, environmental and social criteria are being implemented along with the economic ones to choose design solutions for infrastructures. Using the Ecoinvent database, students will learn about the different impacts caused throughout the life cycle of a railway track, making decisions about its design, and acquiring transversal competencies such as the environmental and ethic responsibility as well as the knowledge of contemporary problems and critical thinking. This article introduces future studies about the life cycle assessment and its applications for the sustainable design of railway infrastructures.
\end{abstract}

Keywords: Life cycle assessment, railway infrastructures, sustainable design, case study.

\section{INTRODUCTION}

Traditionally, civil engineering studies have focused on teaching the required skills to design functional and durable infrastructures while minimizing their economic cost. However, nowadays, new challenges have arisen, such as climate change, that require the introduction of new concepts like sustainable design or construction management. One of the best solutions to address these problems is through a better education of the future professionals in these fields and concepts, which are currently underrepresented in most higher education programs [1-3].

Regarding sustainability, in 1987 the Brundtland Commission defined sustainable development as the kind of development that meets the needs of the present without compromising the ability of future generations to meet their own needs [4]. Thus, sustainability is supported by three pillars of equal importance, economic, environmental and social sustainability [5]. Additionally, these concepts become increasingly important to address in large infrastructure project [6-7], which are designed to last over various generations. Various researchers have made contributions in the design, construction and maintenance of infrastructures considering sustainable criteria, such as bridges [8, 11], roads [12, 13], and walls [14]. However, most of the knowledge required to perform these studies is usually introduced in postgraduate and doctoral courses, while usually being ignored in undergraduate level civil engineering courses. Consequently, to address these issues, engineering courses should be adapted to provide their students with the necessary knowledge to include sustainability in their works.

The transportation sector is one of the main sources of Greenhouse Gas Emissions (GHG), and one of the best solutions to mitigate its impact is the provision of railway infrastructure $[15,16]$, due to its capacity and lower energy consumption [17]. However, the construction of the infrastructure itself causes an important environmental impact, which is not usually properly studied to make decisions regarding the environmental sustainability of the infrastructure. The best method to study these impacts is through the Life Cycle Assessment (LCA) methodology, which considers every process of a system from cradle-to-gate approach and its impacts throughout its service life. Therefore, to introduce 
civil engineering undergraduate students in the design of sustainable infrastructure, a case study is proposed to apply the LCA methodology in the decision-making process of designing a railway infrastructure, acquiring transversal competencies such as the environmental and ethic responsibility as well as the knowledge of contemporary problems and critical thinking. Railway courses are compulsory in most civil engineering bachelor's degrees and constitute the foundation for specializing in this field, thus making this innovation in education widely useful to introduce civil engineering students in incorporating sustainable criteria for their professional future.

\section{METHODOLOGY}

The LCA methodology to quantify and analyze the environmental impacts caused throughout the whole life cycle of a system is carried out according to the ISO 14040 standards [18]. Every phase of the construction of the railway infrastructure itself is considered, including the production of raw materials, the construction of the infrastructure, the maintenance it requires throughout its entire service life, and its final dismantlement and waste treatment in the End of Life (EoL) phase. The particular case of a railway infrastructure is illustrated in Fig. 1 [19].

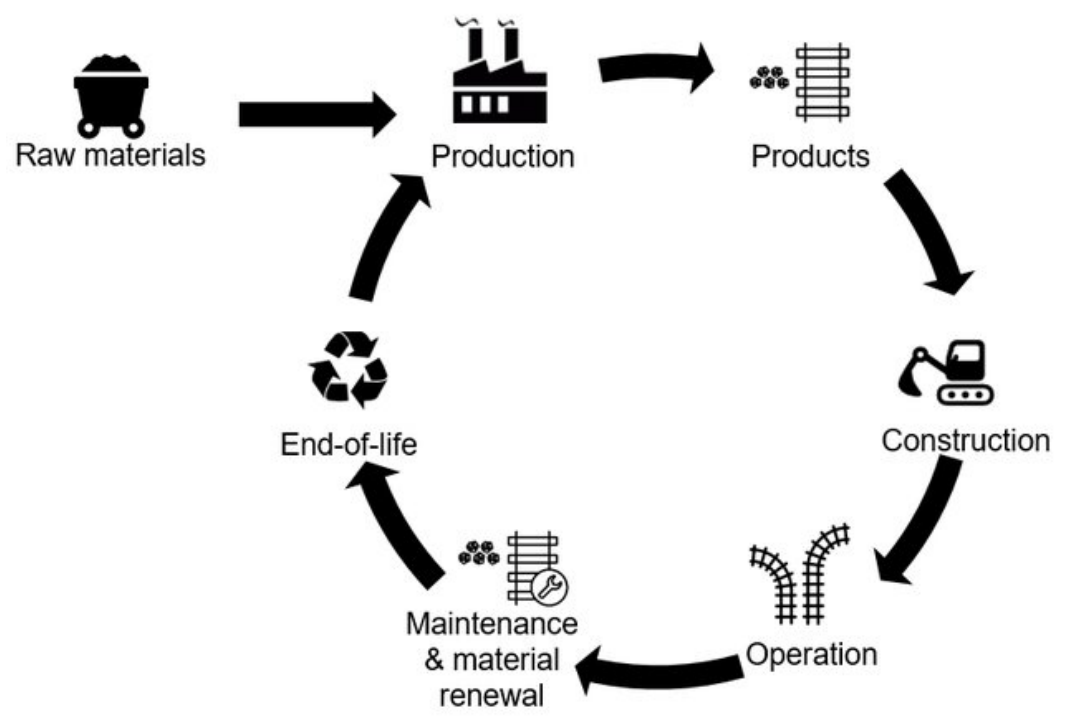

Figure 1. Life Cycle Assessment of the Railway Infrastructure. Source: [19].

Many researchers have applied the LCA methodology to study various aspects of the environmental impact of railway infrastructures [20-22], due to its importance to make decisions on the design and operation of the infrastructure to achieve a more sustainable development. This is because, as previously mentioned, traditionally engineers have focused on reducing the initial economic cost of any project, without properly considering the cost throughout the other phases such as its operation, including the cost of maintenance activities, which are essential for the functionality of most infrastructures, being particularly important in the case of the railways [23, 24].

Therefore, to improve the knowledge of this field, by introducing civil engineering students into its concepts and methodology, a case study is proposed to allow students to develop an LCA study to evaluate the impacts caused by two different alternatives in the design of the railway track bed, a ballast and a concrete track bed. The use of each one is a highly debated theme in railway engineering, depending on the country each design is more commonly constructed. While ballast track beds have relatively lower initial costs, and have been more used popularly for this reason among others, when analyzing the entire life cycle of the infrastructure, concrete track beds, despite their higher initial cost, may have a lower life cycle cost since they require less maintenance activities [25].

To carry out this study, students will use the OpenLCA software [26], an open source Life Cycle and Sustainability assessment software, along with the Ecoinvent database [27], a Life Cycle Inventory database developed by the Eidgenössische Technische Hochschule Zürich (ETHZ), along with other contributors, which is widely used worldwide to carry out many LCA studies, even when using different software tools. Therefore, this will allow the students to learn how to incorporate both the use of new technological tools and the environmental sustainability in their future professional activities as civil engineers, contributing to develop sustainable infrastructure for present and future generations. 


\section{CASE STUDY}

To carry out this case study, two different designs have been selected, a ballast and a concrete track bed for the infrastructure, these examples are shown in Fig. 2. [28, 29]. The data of the materials, machinery and activities has been based on [25], including a typical ballast track in the UK and a Rheda 2000 concrete slab track system. Using the software provided, students have to create a model for both of these systems, considering their entire life cycle, in OpenLCA, using the Ecoinvent database and its processes. The incorporation of these technologies to the original study provides additional possibilities, such as a detailed study of different impact categories depending on which one is deemed to be more important, analyzing the contribution of every material and life cycle phase on the final impact to determine which aspects could be reduced, using different assessment methods, and the possibility to incorporate new processes, such as the land occupation and rail traffic influence on the environment throughout its service life or the waste treatment processes in the EoL phase.
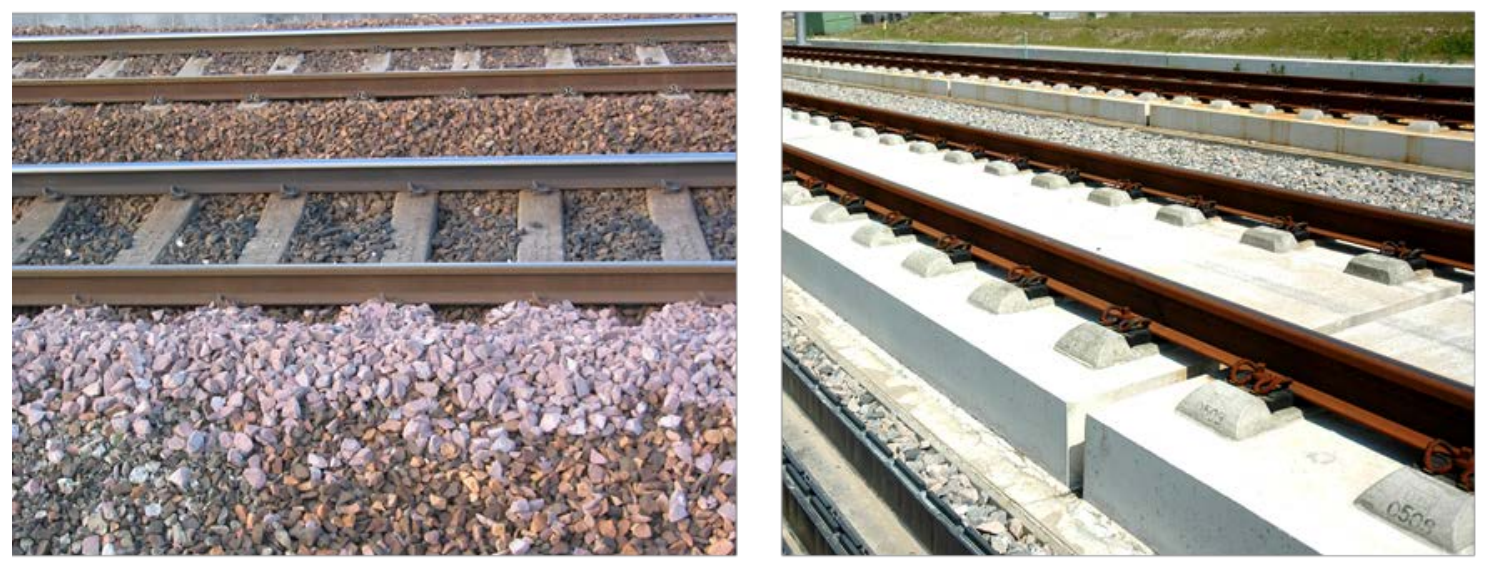

Figure 2. Ballast and concrete track beds. Sources: [28, 29].

The functional unit of the study is the life cycle of a kilometer of railway track, to allow a comparison between two homogenic units. A service life of 30 years and 60 years have been considered to compare the performance of the different solutions depending on their lifetime.

For this case study, the activities related to the infrastructure itself have been considered to determine its environmental impact. These activities are the extraction and production of raw materials for their use in the infrastructure, mainly steel and the processes required to produce a rail, like alloying the metals and hot rolling to produce the final section, the extraction and crushing of stones to conform the ballast, the production of concrete for the sleepers and the concrete bed etc.

In the construction phase, the impacts are caused by the operation of building machines, like sleeper, rail laying and ballast spreading machines for the ballast track and an in-situ slab former, rail laying machine, and a concrete truck for the concrete truck.

The maintenance phase has been modelled considering the average service life of the components that need to be replaced throughout the life cycle of the tracks, like the rails and fastenings, sleepers and track pads. In the case of the ballast track, additional maintenance activities are required continuously throughout its operation due to the degradation of the ballast caused by the train traffic. These activities include the tamping of ballast to make the tracks more durable and its cleaning, which require special machinery to be performed and the addition of new ballast on the track bed during these activities. The occupation of land and train traffic have also been considered in this phase.

For the EoL phase, the dismantling of every track component, considering the operation of the machinery required to carry out these operations and the waste treatment processes for the remains of the materials, like the steel and concrete recycling, the crushing and deposition in a landfill of the materials that cannot be recycled like the contaminated ballast etc.

Additionally, ballast tracks are expected to serve up to 30 years, after which the ballast track bed should be replaced for a new one, but most of the steel materials used for the rails, reinforcement bars and fastenings can be recycled, which reduces significantly the impact caused by the reconstruction of the ballast bed after its initial service life has ended. However, concrete slab tracks have a higher life expectancy, between 60 and 100 years, requiring only the replacement of the other components of the 
track during its service life. Therefore, to include these variations, the students have to consider the service life for which the infrastructure is projected to last, modelling the maintenance phase accordingly to the activities required throughout that time. For this study, two periods have been considered, a 30-year one, after which both tracks would finish their service life, and a 60-year period, which requires the dismantlement and reconstruction of the ballast track after 30 years, while the concrete track can last that period without any activities besides the replacement of components. After their service life has ended, the infrastructure must be dismantled, reusing, recycling or disposing them by burial in a landfill, depending on the material.

To evaluate the impacts caused by the entire system, the software allows the use of different methods. Every method provides different impact categories to analyze the affections on the environment throughout its service life, so the election on one or another could be considered a subjective question, which is up for the students to decide. For this paper, the ReCiPe [30] method has been considered, because it provides the possibility of using two different approaches to evaluate the environmental impact, a midpoint approach that considers many categories for a detailed study on specific affections to the environment such as the $\mathrm{CO}_{2}$ emissions or the water depletion; and an endpoint approach that combines these categories in three damage categories: to the ecosystems, human health, and resources, providing a wider perspective which is easier to interpret to analyze the total environmental impact. These categories can be normalized and compared between each other.

\subsection{Midpoint approach results}

The midpoint approach considers 18 impact categories, which provide a complete detailed study on certain emissions or impacts but can be hard to interpret as a whole to study the global impact of the infrastructure due to the number of categories. The impacts obtained for the LCA of the tracks considered for a service life of 60 years is shown in Table 1. The results have an associated uncertainty; however, to compare them their mean values are displayed.

Table 1. Midpoint approach results for a service life of 60 years.

\begin{tabular}{|c|c|c|c|}
\hline Impact Category & Reference Unit & Ballast Track & Concrete Track \\
\hline Agricultural land occupation & $m^{2 *} a$ & 18410.38 & 16349.74 \\
\hline Climate Change & $\mathrm{kg} \mathrm{CO}_{2}$ eq & 608606.19 & 812706.44 \\
\hline Fossil depletion & $\mathrm{kg}$ oil eq & 132492.36 & 130858.70 \\
\hline Freshwater ecotoxicity & $\mathrm{kg} \mathrm{1,4-DB} \mathrm{eq}$ & 18982.37 & 19083.22 \\
\hline Freshwater eutrophication & $\mathrm{kg} \mathrm{P}$ eq & 388.99 & 394.42 \\
\hline Human toxicity & kg 1,4-DB eq & 573581.23 & 593721.32 \\
\hline lonizing radiation & $\mathrm{kg} \cup 235 \mathrm{eq}$ & 42017.12 & 34138.09 \\
\hline Marine ecotoxicity & $\mathrm{kg} 1,4-\mathrm{DB}$ eq & 18192.39 & 18402.56 \\
\hline Marine eutrophication & $\mathrm{kg} \mathrm{N} \mathrm{eq}$ & 128.31 & 120.22 \\
\hline Metal depletion & $\mathrm{kg} \mathrm{Fe} \mathrm{eq}$ & 567550.79 & 620639.54 \\
\hline Natural land transformation & $\mathrm{m}^{2}$ & 252.83 & 75.15 \\
\hline Ozone depletion & kg CFC-11 eq & 0.04 & 0.03 \\
\hline Particulate matter formation & kg PM10 eq & 2097.23 & 2098.95 \\
\hline Photochemical oxidant formation & kg NMVOC & 2633.00 & 2544.77 \\
\hline Terrestrial acidification & $\mathrm{kg} \mathrm{SO}_{2}$ eq & 2620.97 & 2563.07 \\
\hline Terrestrial ecotoxicity & $\mathrm{kg} 1,4-\mathrm{DB}$ eq & 65.21 & 66.72 \\
\hline Urban land occupation & $\mathrm{m}^{2 *} \mathrm{a}$ & 1325748.47 & 1321090.43 \\
\hline Water depletion & $\mathrm{m}^{3}$ & 3296282.82 & 3255179.23 \\
\hline
\end{tabular}

Both designs present similar values in most categories, with a few exceptions. This further proves the fact that there is an ongoing debate between which solution is better, since there are few differences between their environmental impacts and both of them have their own advantages and disadvantages. However, with this case study, students can notice the impact caused by the manufacturing of cement 
and concrete, one of the main factors of $\mathrm{CO}_{2}$ emissions globally, since even when considering the diesel consumption of all the machinery required for the maintenance of the ballast track through its entire operation phase, the concrete track still produces almost a $25 \%$ higher amount of $\mathrm{CO}_{2}$ emissions, mainly caused by the cement production required for its construction. However, the amount of ballast required for the ballast track causes a significant increase in the natural land transformation, almost 3.4 times higher than the concrete track, because of the amount of materials that require to be extracted from natural sources for the ballast bed. The concrete track requires more metal than the ballast one for the reinforcements of the concrete bed, while the ballast track consumes more fossil fuels required for the maintenance activities.

\subsection{Endpoint approach results}

The endpoint approach groups the midpoint impact categories in three damage categories, to the ecosystems, human health, and resources. These categories provide a global vision of the damage caused to the main components of the environment throughout the life cycle of the infrastructure. Even though each category is measured in a different unit, a normalization and weighting set provided by the method can be applied to compare these categories in a global unit, the impact points. Therefore, the different contribution of every process to each damage category and the global impact can be measured to easily determine differences between the different proposed alternatives.

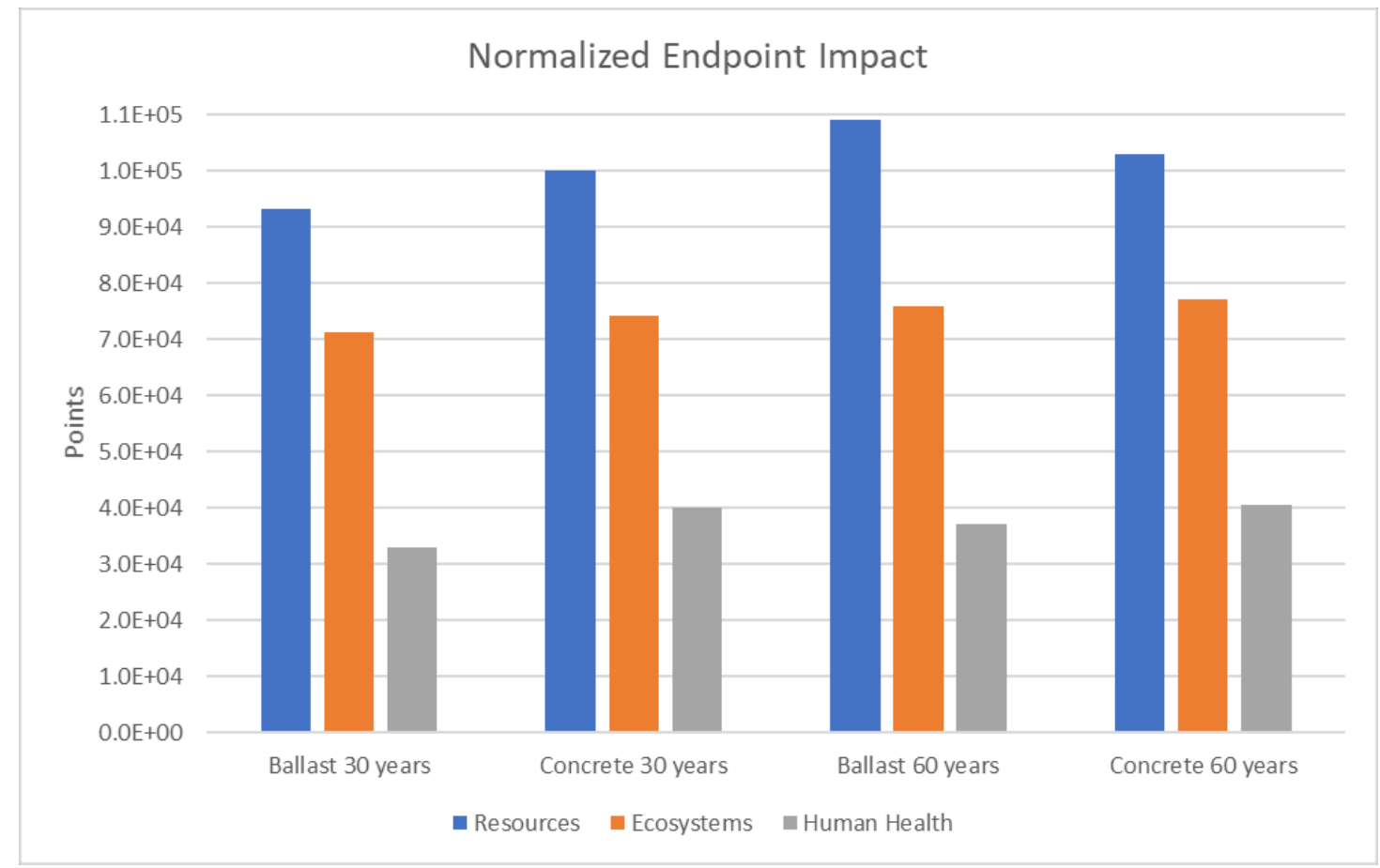

Figure 3. Ballast and concrete track beds.

The normalized endpoint impacts for the different solutions, categories and service lives considered is displayed in Fig. 3. As it could be deduced from the midpoint impact results, the impacts caused by both alternatives are very similar in most categories, with a few slight differences. Both periods have been considered to quantify the evolution of each solution depending on its service life. For a service life of 30 years, the ballast track presents lower impacts in the three damage categories, presenting a higher difference in the resources and human health categories between both alternatives. However, when considering a longer service life of 60 years, due to the required maintenance activities and reposition of components, both designs increase their impacts, but while the concrete track conserves very similar values, the ballast track significantly increases its damage to the resources, while also slightly increasing its damage to the ecosystems and human health.

To determine which activities are responsible for most of these emissions, the contribution of each phase and activity can be visualized for every damage category. This allows the possibility to reduce the impacts caused by a certain activity after realizing its contribution, for example, by reducing the amount of cement in the concrete track or the amount of ballast in the ballast track, whenever it is 
possible to do so. Fig. 4 and 5 represent the contribution of every phase of the life cycle of the railway infrastructure for the different damage categories. A service life of 60 years is determined to further analyze which activities are responsible for the increment in the different damage categories.

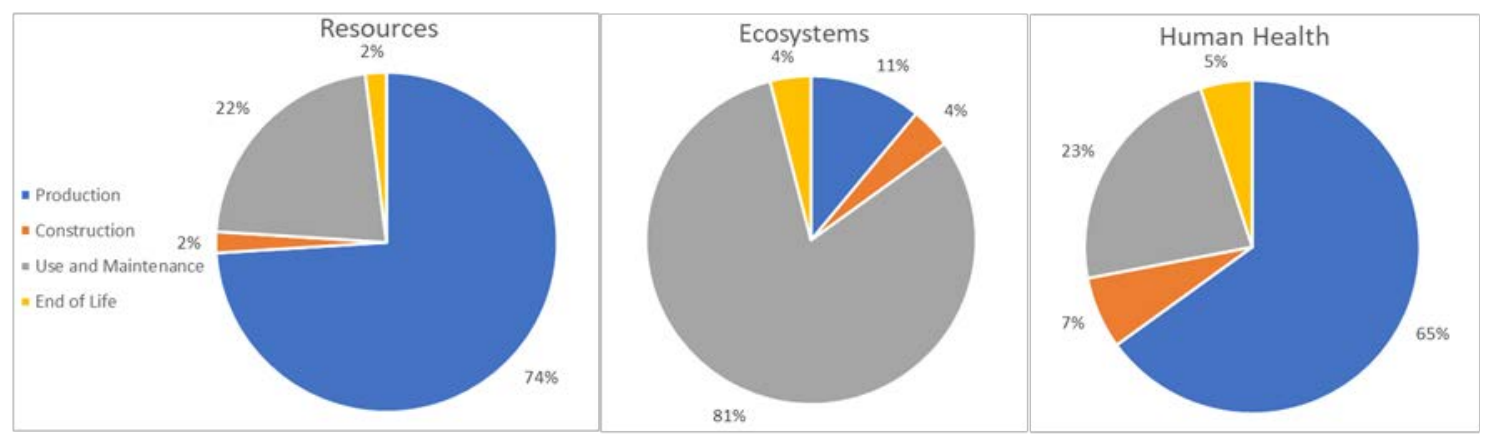

Figure 4. Damage contribution of the ballast track phases.
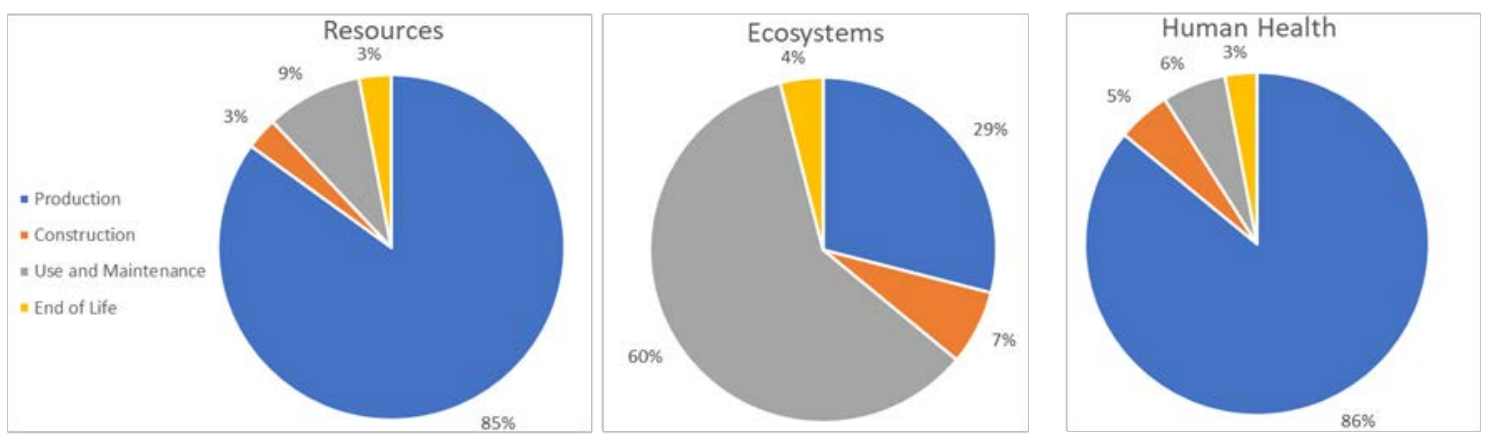

Figure 5. Damage contribution of the concrete track phases.

The production phase contributes for most of the damage to the resources in both cases, due to the amount of materials that are required for the construction of the railway track. However, it accounts for $11 \%$ in the case of the concrete track, while the use and maintenance phase increases its contribution by $13 \%$ in ballast track, mainly because of the additional maintenance activities that it requires and the fuel consumption of these machines during the maintenance phase. Regarding the ecosystems, the use and maintenance phase of the ballast track accounts for a $21 \%$ higher contribution than the concrete one, caused by the emissions of the maintenance operations, however, the contribution of the damage caused by the initial production of materials is greater in the concrete track, due to the emissions produced by the cement and concrete manufacturing processes. Finally, the damage caused to the human health is mainly caused by the production phase in both alternatives, being even greater in the concrete track, while the use and maintenance phase accounts for a greater amount in the ballast track when relatively compared for the same reasons previously explained.

Therefore, the production phase accounts for most of the damage caused to the resources and human health while the use and maintenance phase is responsible for most of the damage caused to the ecosystems, mainly due to the land occupation, and in the case of the ballast track, the fuel consumption of the maintenance operations required during its service life. These operations also increase the contribution of the use and maintenance phase of the ballast track for every category, which is mainly noticeable in the resources and human health categories when compared with the concrete track alternative.

\section{CONCLUSIONS}

This article has presented the introduction of the LCA methodology for undergraduate civil engineering students, applied to a case study in railway design, one of the main fields of civil engineering and a compulsory course in most civil engineering programmes worldwide. The LCA methodology allows the incorporation of environmental sustainability in the design of any system, even complex ones like the construction and operation of large infrastructure projects, as well as the use of new technologies. The 
growing concerns for the environment have changed the traditional perspective of most civil engineering projects to consider the minimisation of only their economic cost, but these concepts are currently not properly introduced in education, even when they are becoming increasingly important nowadays to combat climate change.

For this reason, a case study is developed for students to learn how to evaluate and incorporate environmental sustainability to make decisions accordingly, along with the traditional objective of the reduction of the economic cost. The case study also allows the students to acquire transversal competencies such as the environmental and ethic responsibility as well as the knowledge of contemporary problems and critical thinking, along with the technical knowledge usually taught in engineering subjects, improving the quality of their professional education.

In the particular case of deciding between using a ballast track bed or a concrete one, which is one of the most important debates in railway engineering nowadays, by evaluating their complete life cycle, it can be concluded that even though the initial costs of the concrete track are higher, both economically and environmentally, when considering the entire life cycle of the infrastructure for long periods of time, the maintenance activities of the ballast track cause a significant environmental impact, which becomes more noticeable when considering longer periods of service life since its components require additional maintenance and reposition than the ones for the concrete track. However, the environmental impact of both alternatives is similar, but the ballast track becomes worse than the concrete one for various impacts as its service life increase, thus, if a longer period than 60 years was considered for both alternatives, the concrete track would clearly become a more sustainable solution than the ballast track, while for a period of 30 years the ballast track remains the cleanest alternative.

Finally, this article can be used to introduce future studies about the life cycle assessment and its applications for the sustainable design of an infrastructure for civil engineering students and professionals, with a particular case study in the application for railway infrastructures.

\section{ACKNOWLEDGEMENTS}

The authors acknowledge the financial support of the Spanish Ministry of Economy and Competitiveness, along with FEDER funding (Project: BIA2017-85098-R).

\section{REFERENCES}

[1] C. Torres-Machí, A. Carrión, V. Yepes, and E. Pellicer, "Employability of Graduate Students in Construction Manahttp://prezi.com/gement," J. Prof. Issues Eng. Educ. Pract., vol. 139, no. 2, pp. 163-170, 2013.

[2] E. Pellicer, V. Yepes, C. L. Correa, and L. F. Alarcón, "Model for Systematic Innovation in Construction Companies," J. Constr. Eng. Manag., vol. 140, no. 4, p. B4014001, 2014.

[3] E. Pellicer, L. A. Sierra, and V. Yepes, "Appraisal of infrastructure sustainability by graduate students using an active-learning method," J. Clean. Prod., vol. 113, pp. 884-896, 2016.

[4] World Commission on Environment and Development., Our common future. Oxford University Press, 1987.

[5] L. A. Sierra, V. Yepes, and E. Pellicer, "A review of multi-criteria assessment of the social sustainability of infrastructures," J. Clean. Prod., vol. 187, pp. 496-513, 2018.

[6] L. A. Sierra, E. Pellicer, and V. Yepes, "Social Sustainability in the Lifecycle of Chilean Public Infrastructure," J. Constr. Eng. Manag., vol. 142, no. 5, p. 05015020, 2016.

[7] F. Biondini and D. M. Frangopol, "Life-Cycle Performance of Civil Structure and Infrastructure Systems: Survey,” J. Struct. Eng., vol. 144, no. 1, p. 06017008, 2018.

[8] V. Penadés-Plà, T. García-Segura, J. Martí, V. Yepes, V. Penadés-Plà, T. García-Segura, J. V. Martí, and V. Yepes, "A Review of Multi-Criteria Decision-Making Methods Applied to the Sustainable Bridge Design," Sustainability, vol. 8, no. 12, p. 1295, 2016.

[9] J. V. Martí, T. García-Segura, and V. Yepes, "Structural design of precast-prestressed concrete Ubeam road bridges based on embodied energy," J. Clean. Prod., vol. 120, pp. 231-240, 2016.

[10] T. García-Segura, V. Yepes, D. M. Frangopol, and D. Y. Yang, "Lifetime reliability-based optimization of post-tensioned box-girder bridges," Eng. Struct., vol. 145, pp. 381-391, 2017. 
[11] V. Penadés-Plà, T. García-Segura, and V. Yepes, "Accelerated optimization method for lowembodied energy concrete box-girder bridge design," Eng. Struct., vol. 179, pp. 556-565, 2019.

[12] A. Carbonell, F. González-Vidosa, and V. Yepes, "Design of reinforced concrete road vaults by heuristic optimization," Adv. Eng. Softw., vol. 42, no. 4, pp. 151-159, 2011.

[13] C. Torres-Machi, A. Chamorro, V. Yepes, and E. Pellicer, "Current models and practices of economic and environmental evaluation for sustainable network-level pavement management," Revista de la construcción, vol. 13, no. 2, pp. 49-56, 2014.

[14] P. Zastrow, F. Molina-Moreno, T. García-Segura, J. V. Martí, and V. Yepes, "Life cycle assessment of cost-optimized buttress earth-retaining walls: A parametric study," J. Clean. Prod., vol. 140, pp. 1037-1048, 2017.

[15] S. Saxe, G. Casey, P. Guthrie, K. Soga, and H. Cruickshank, "Greenhouse gas considerations in rail infrastructure in the UK," Proc. Inst. Civ. Eng. - Eng. Sustain., vol. 169, no. 5, pp. 171-180, 2016.

[16] D. Y. Yang and D. M. Frangopol, "Societal risk assessment of transportation networks under uncertainties due to climate change and population growth," Struct. Saf., vol. 78, pp. 33-47, 2019.

[17] P. Salvador, P. Martínez, I. Villalba, and R. Insa, "Modelling energy consumption in diesel multiple units," Proc. Inst. Mech. Eng. Part F J. Rail Rapid Transit, vol. 232, no. 5, pp. 1539-1548, 2018.

[18] ISO, "ISO 14040:2006 - Environmental management -- Life cycle assessment -- Principles and framework," 2006. [Online]. Available: https://www.iso.org/standard/37456.html. [Accessed: 27Dec-2018].

[19] A. Merchan Arribas, S. Belboom, and A. Léonard, "Life Cycle Assessment of railway infrastructure in Belgium," in [avniR] conference. Life Cycle Management, the pathway for ecotransition. 2017 Conference proceedings, 2017, pp. 159-162.

[20] Y. Yue, T. Wang, S. Liang, J. Yang, P. Hou, S. Qu, J. Zhou, X. Jia, H. Wang, and M. Xu, "Life cycle assessment of High Speed Rail in China," Transp. Res. Part D Transp. Environ., vol. 41, pp. 367-376, 2015.

[21] H. Jones, F. Moura, and T. Domingos, "Life cycle assessment of high-speed rail: a case study in Portugal," Int. J. Life Cycle Assess., vol. 22, no. 3, pp. 410-422, 2017.

[22] S. Bressi, G. D'Angelo, J. Santos, and M. Giunta, "Environmental performance analysis of bitumen stabilized ballast for railway track-bed using life-cycle assessment," Constr. Build. Mater., vol. 188, pp. 1050-1064, 2018.

[23] L. F. Caetano and P. F. Teixeira, "Optimisation model to schedule railway track renewal operations: a life-cycle cost approach," Struct. Infrastruct. Eng., vol. 11, no. 11, pp. 1524-1536, 2015.

[24] L. F. Caetano and P. F. Teixeira, "Predictive Maintenance Model for Ballast Tamping," J. Transp. Eng., vol. 142, no. 4, p. 04016006, 2016.

[25] M. Kiani, T. Parry, and H. Ceney, "Environmental life-cycle assessment of railway track beds," Proc. Inst. Civ. Eng. - Eng. Sustain., vol. 161, no. 2, pp. 135-142, 2008.

[26] GreenDelta, "OpenLCA," 2006. [Online]. Available: http://www.openlca.org/. [Accessed: 30-Dec2018].

[27] ecoinvent, "Ecoinvent Database." [Online]. Available: https://www.ecoinvent.org/. [Accessed: 30Dec-2018].

[28] Wikimedia Commons, "Track ballast," 2005. [Online]. Available: https://commons.wikimedia.org/wiki/File:Rails.and.ballast.bb.jpg. [Accessed: 30-Dec-2018].

[29] Wikimedia Commons, "Ballastless track," 2005. [Online]. Available: https://commons.wikimedia.org/wiki/File:RHEDA_2000_-_12.JPG. [Accessed: 30-Dec-2018].

[30] M. Goedkoop, R. Heijungs, M. Huijbregts, A. De Schryver, J. Struijs, and R. Van Zelm, "ReCiPe 2008," Rep. I Characterisation, no. January, pp. 1-44, 2009. 